\title{
A Paediatric HIV Care and Treatment Programme in Malawi
}

\section{Mark M Kabue $^{1}$, Chimwemwe Chitsulo ${ }^{1}$, Peter N Kazembe ${ }^{1}$, Michael B Mizwa ${ }^{2}$, Nancy R Calles $^{2}$}

1. Baylor College of Medicine-Abbott Fund Children's Clinical Care Centre of Excellence-Malawi

2. Baylor College of Medicine International Paediatric AIDS Initiative

Corresponding author Dr. Mark Kabue, Baylor College of MedicineAbbott Fund Children's Clinical Care Centre of Excellence-Malawi, Lilongwe, Malawi Email address: mkabue@baylor-malawi.org

\section{Introduction}

In Malawi, Acquired Immunodeficiency Syndrome (AIDS) is a major cause of death among 15 - 49 year olds. It is estimated that 900,000 adults and children live with HIV/AIDS in Malawi, a country where the HIV/AIDS prevalence in adults (15-49 years) was $14.1 \%$ in $2005^{1,2}$.In 2005, an estimated 170,000 people were in immediate need of antiretroviral therapy (ART) with children below 15 years accounting for nearly $15 \%$ of the those needing ART in Malawi ${ }^{3}$. In 2001, the Ministry of Health (MoH) introduced subsidized antiretrovirals (ARVs) in three referral hospitals in the three regions of Malawi, rapidly scaling up national access to free ARVs and also introduced a programme for the prevention of mother$\mathrm{t}$ o - c h i l d transmission of HIV (PMTCT). Until 2005 Malawi's ART program m e focused almost entirely on adults $^{2,3}$. A majority of HIV-infected infants and children were treated symptomatically in the general paediatric clinics with few receiving treatment through the adult ART programme.

The Baylor College of Medicine-Abbott Fund Children's Clinical Centre of Excellence-Malawi (COE) is the first standalone clinic in Malawi dedicated to the care and treatment of HIV-infected children, and training of different cadres of health professionals in the management of paediatric $\mathrm{HIV} / \mathrm{AIDS}^{4}$. The COE is part of a network of clinics established by the Baylor International Paediatric AIDS Initiative (BIPAI) whose headquarters is in Houston, Texas, United States of America. The BIPAI network comprises of centres of excellence in Romania, Botswana, Lesotho, Uganda, Swaziland, and Malawi that provide care and treatment to HIV-infected children and families who qualify to be enrolled in the family clinic. Two additional centres of excellence are in the processes of being established in Kenya and Burkina Faso. BIPAI is also working with partners in Libya and Tanzania. The Malawi COE is located within the grounds of Kamuzu Central Hospital (KCH), a government facility in Lilongwe. The COE was officially opened on 2 nd
November, 2006. The COE is operated by a locally registered trust known as Baylor College of Medicine Children's Foundation - Malawi.

\section{Patient care and training}

The clinical and training functions of the programme are categorized into five levels: 1) patient care and training activities at the COE; 2) patient care at outreach sites in Lilongwe district; 3) patient care, training and supervision at outreach sites in all the other districts in the central region of Malawi; 4) patient care, training and supervision at distant sites in the southern and northern regions of Malawi; and 5) participation in national policy-level activities pertaining to paediatric HIV care. In addition to the comprehensive care and treatment provided to paediatric patients at the COE, a family clinic has been established whereby the HIV-infected child is the point of entry into the programme for the entire family. In the family clinic, HIV-infected adults and siblings of the index child also access care at the COE. All HIVinfected and HIVexposed children are routinely p r e s c r i b e d cotrimoxazole on monthly basis, provided with an insecticide-treated net, and a tablet splitter or pill cutter since a fixeddose combination ( Triom un e : S t a v u d i n e, Lamivudine \& Niverapine) is the most commonly prescribed antiretroviral for paediatric patients in Malawi. A few patients are on antiretroviral syrup formulations mainly second line regimens, courtesy of the Clinton Foundation.

The paediatric HIV care training is based on a curriculum developed by BIPAI with input from HIV/AIDS health care professionals from southern and eastern Africa. The training programme in Malawi commenced in October 2006 and to date has provided comprehensive paediatric HIV care and treatment training to healthcare personnel of various cadres nation-wide 5 . In 2007 we trained 813 health professionals; 111 clinicians (doctors and clinical officers), 20 nurses, 45 medical assistants, 81 counsellors, 54 pharmacy technicians, 288 health surveillance assistants, and 7 in other cadres. Through a combination of didactic training and clinical mentoring, the training programme aims to support the efforts of the Ministry of Health to increase the capacity of health centres in the provision and scale-up of care and treatment services to HIV-infected children. An intensive one-day training session comprising didactic presentations on a range of clinical, psychosocial and public health topics 
pertinent to paediatric HIV is held at a district level. A series of follow-up visits to ARV sites in each district are carried out, during which Baylor clinicians carry out practical in-clinic sessions on direct patient care. In Lilongwe district, outreach sites have been established at six national ART sites where Baylor clinicians provide HIV care and treatment services and mentor clinical staff at these sites. Clinical officers from district health centres where training has been conducted spend a week-long attachment at the COE. Attachments to the COE, enhances visiting clinicians self efficacy and experience.

\section{Counselling, testing, and inpatient care}

HIV/AIDS testing and counselling (HTC) is one of the key entry points into the programme. The COE and Lighthouse Trust HTC counselors work jointly operating from the $\mathrm{KCH}$ paediatric ward, serving both in-patients and out-patients. This has resulted in a reduction in missed opportunities for early identification of HIV-infected children. The COE is physically attached to $\mathrm{KCH}$ paediatric ward this ensures timely identification and enrolment of both HIV-exposed and HIV-infected children. Every effort is made not to offer HTC to potential COE patients especially those who are admitted to the Nutritional Rehabilitation Unit (NRU) at $\mathrm{KCH}$. The COE staff in the paediatric ward consists of two paediatricians and a nurse who work hand in hand with $\mathrm{KCH}$ staff on daily basis to provide comprehensive paediatric care to both HIV-infected and uninfected children in the ward. The COE is also a recognized outpatient therapeutic programme (OTP) site for the management of moderately malnourished HIV-infected children. CD4+ cell counts are measured for all HIV infected patients every six months while only those who are suspected of treatment failure have their viral loads measured.

\section{Methods}

The programme utilizes multiple data collection methods, primarily an electronic medical records (EMR) system. Data were also collected from the following registers; daily patient attendance register, new patients register, ARV register, OTP programme (Nutrition) register, and social worker home visits (intensive follow up) register.
An evaluation of the programme was carried out in September 2007, that utilized two approaches: a two group non-randomized pretest post-test (case-control ) to assess medical records of paediatric patients, and a cross-sectional study to asses the level of satisfaction with services provided from a sample of programme users (caregivers and patients) and programme staff (providers). Electronic medical records of 129 patients on ARVs and 129 not on ARVs without identifiers were reviewed. The evaluation was based on data collected from the beginning of the programme in October 2004 to June 30, 2007. Selection of the medical records for retrospective review was based on ARV status (either on ARVs or not on ARVs). The patients were those registered by December 31, 2006 and still active by June 30, 2007 to ensure that each patient had data for at least six months.

Two hundred and twenty-two caregivers (programme users) and twenty-one programme staff (providers) participated in face-to-face interviews to gather information on programme delivery. Consent was obtained and interviews conducted primarily in Chichewa among the caregivers although English was used in some cases depending on the literacy level of the caregiver. The evaluation study was approved by both the Malawi National Health Sciences Research Committee (NHSRC) and the Baylor College of Medicine institutional review board. Data were collected during August and September 2007 then analyzed in stages starting with descriptive statistics to more advanced procedures. The Chisquare and Fisher's exact tests were used to characterize the study population. Odds Ratios (OR) were calculated where possible to illustrate the strength of association. Weight-forheight-and-age percentiles were calculated using Epi-Info 2000 and World Health Organization reference growth charts (WHO 1978 reference). Stata software version 9.0 (College station, Texas, USA) was the principal statistical package used for data analyses. P-value and 95\% confidence interval were used to determine levels of significance. A p-value of $<0.05$ was considered statistically significant.

\section{Results}

\section{Description of the cohort}

By June 30 2007, a total of 1917 paediatric patients $(<18$ years) and 36 adults had been enrolled in the programme. No further analysis was carried out on the adult patients in

Table 1: Baseline characteristics of the study population

\begin{tabular}{|l|l|l|l|l|}
\hline Variable & \multicolumn{4}{|c|}{ Age category } \\
\hline & $<18$ months & 18 months to 5years & $>5$ years to 18years & Total \\
\hline Sex $(\mathrm{N}=1917)$ & & & & \\
\hline Male & $340(50.7 \%)$ & $302(53.9 \%)$ & $355(51.7 \%)$ & $997(52.0 \%)$ \\
\hline Female & $330(49.3 \%)$ & $258(46.1 \%)$ & $332(48.3 \%)$ & $920(48.0 \%)$ \\
\hline Weight for height $(\mathrm{n}=1056)$ & & & & \\
\hline$<70 \%$ & $281(85.7 \%$ & $322(85.4 \%)$ & $282(80.3 \%)$ & $885(83.8 \%)$ \\
\hline$>70 \%$ to $80 \%$ & $17(5.2 \%)$ & $20(5.3 \%)$ & $24(6.9 \%)$ & $61(5.8 \%)$ \\
\hline$>80 \%$ & $30(9.1 \%)$ & $35(9.3 \%)$ & $451(2.8 \%)$ & $110(10.4 \%)$ \\
\hline Body mass index $(\mathrm{n}=798)$ & & & & $15.1(6.1-31.5)$ \\
\hline $\begin{array}{l}\text { Median } \mathrm{BMI}\left(\mathrm{kg} / \mathrm{m}^{2}\right) \\
\text { (range) }\end{array}$ & Not calculated & $15.5(7.8-20.1)$ & $15.1(6.1-31.5)$ & $15.2(6.1-31.5)$ \\
\hline Mean BMI & Not calculated & 15.3 & 15.2 &
\end{tabular}




\begin{tabular}{|l|l|l|l|l|}
\hline Variable & \multicolumn{2}{|l|}{ Proportions and means } & & \\
\hline & On ARVs & No ARVs & $\begin{array}{l}\text { Odds } \\
\text { ratio }\end{array}$ & $p$-value \\
\hline Sex & Male=59\% & Male=36\% & 2.6 & $<0.05$ \\
\hline Age at enrolment & & & & \\
\hline & $\mu=4.8$ years & $\mu=4.8$ years & & 0.70 \\
\hline $\begin{array}{l}\text { HIV-infected at } \\
\text { enrolment }\end{array}$ & $91 \%$ & $81 \%$ & 2.5 & $<0.05$ \\
\hline $\begin{array}{l}\text { Received PMTCT } \\
\text { (sdNVP) }\end{array}$ & $29 \%$ & $21 \%$ & 0.6 & 0.14 \\
\hline WHO stages 3 \& 4 & $85 \%$ & $34 \%$ & 11.1 & $<0.05$ \\
\hline $\begin{array}{l}\text { Malnutrition } \\
\text { present }\end{array}$ & $10 \%$ & $6 \%$ & 1.8 & $<0.05$ \\
\hline PCP prophylaxis & $98 \%$ & $99 \%$ & 0.8 & 0.51 \\
\hline Admission history* & $1 \%$ & $0.4 \%$ & $2.7^{*}$ & 0.56 \\
\hline $\begin{array}{l}\text { Mean baseline } \\
\text { CD4 count }\end{array}$ & 561.8 & 1058.8 & & $<0.05$ \\
\hline $\begin{array}{l}\text { Mean baseline } \\
\text { CD4 \% }\end{array}$ & 13.8 & 26.2 & & $<0.05$ \\
\hline * One cell & & & \\
\hline
\end{tabular}

* One cell had less than 5 members; Fisher's exact $p$-value quoted. All other $p$-values are Chi2

the family clinic. Mean age at enrolment was 4.2 years and median age was 2.5 years [range 0.03-19.1]. About half of all enrolled paediatric patients $(49.9 \%)$ had ever been started on ARVs by June 30,2007 . Paediatric patient's gender was male $(52 \%)$ and female (48\%). Over eighty percent of all enrolled patients had a weight-for-height-and-age below $70 \%$, and the median body mass index (BMI) was 15.1 (6.1-31.5) as shown in table 1.

Over half $(58.1 \%)$ the patients were considered active since they had attended at least one clinic visit in the preceding six months, $17.7 \%$ were lost to follow up, $10.5 \%$ have died, $10.6 \%$ transferred out, and 3.1\% had their files closed after ascertainment of HIV-negative status among HIV-exposed infants. Over $80 \%$ of patients reported as "lost to followup" had not been started on ARVs at the time they stopped accessing care. Since the start of the programme in 2004, a total of 202 infants and children had died with a majority of the deaths occurring during the first three months of enrolment into the programme. Patients aged below five years contributed to nearly three-quarters of the total deaths. The majority of deaths among the patients on ARVs occurred during the first three months of enrolment. Only three patients have been stopped from receiving ARVs due to poor adherence; none have been discontinued due to adverse effects of ARVs. The median follow up time on ARVs at the COE was 42 weeks, range ( $0-136$ weeks).

Only thirty-nine patients had viral loads done by June 2007 due to suspected immunologic failure of whom twentyfive of them had detectable viral load ( $>400$ copies $/ \mathrm{ml})$ and fourteen had undetectable viral load $(<400$ copies $/$ $\mathrm{ml})$. A total of fifty patients had been switched from the standard first-line regimen in Malawi (Triomune: Stavudine, Lamivudine \& Niverapine) to either an alternative first-line (22 patients) or a second line (28 patients) regimen. Main reasons for change of ART regimen to alternative first-line were hypersensitivity to Niverapine, peripheral neuropathy,

\begin{tabular}{|l|l|l|l|}
\hline Score & $\begin{array}{l}\text { Doctors } \\
(\mathrm{N}=9)\end{array}$ & $\begin{array}{l}\text { Other health } \\
\text { professionals }(\mathrm{N}=12)\end{array}$ & $\begin{array}{l}\text { Caregivers } \\
(\mathrm{N}=222)\end{array}$ \\
\hline Very satisfied (5) & 1 & 2 & 171 \\
\hline Satisfied (4) & 8 & 9 & 46 \\
\hline Neutral (3) & 0 & 1 & 3 \\
\hline Unsatisfied (2) & 0 & 0 & 0 \\
\hline Very unsatisfied (1) & 0 & 0 & 0 \\
\hline Mean & 4.1 & 4.1 & 4.8 \\
\hline
\end{tabular}

and pancreatitis.

\section{Comparison by ARV status}

Table 2 summarizes the comparison of the two groups on key demographic and clinical characteristics. A total of 258 medical records were reviewed; 129 on ARVs and 129 not on ARVs. Mean age at enrolment in each of the two groups was 4.8 years. The proportion of males among those on ARVs $(59 \%)$ was significantly higher than among those not on ARVs (36\%), and males were 2.6 times more likely to be on ARVs compared to females $(\mathrm{p}<0.05)$. Patients who had a confirmed HIV-positive diagnosis at enrolment were 2.5 times more likely to have been on ARVs compared to those who were HIV-exposed at enrolment $(p<0.05)$. Patients in either WHO stage III or IV at enrolment were 11.1 times more likely to be on ARVs compared to those in either WHO stage I or II $(p<0.05)$. Presence of malnutrition was more pronounced among those on ARVs. Baseline absolute CD4+ cell count and percent was significantly lower (about half) among patients on ARVs compared to those not on ARVs $(\mathrm{p}<0.05)$. Both the mean absolute CD4+ and percent doubled from 562 to 1280 cells $/ \mathrm{mm}^{3}$ and $14 \%$ to $28 \%$ respectively in nearly thirty months $(\mathrm{p}<0.05)$ among patients on ARVs.

\section{Interviews}

Nearly $90 \%$ of the caregivers (programme users) were females, and $65 \%$ of the caregivers were the reported biological mother of the child/patient. Other caregivers included aunts $(12.6 \%)$, fathers $(5.9 \%)$, grandmothers $(5 \%)$, and sisters (4\%). About half of the caregivers either had no formal schooling or only primary level education. Only about half of the caregivers were employed (full time or self employment) while $42.3 \%$ were unemployed. Table 3 shows that the level of satisfaction of services offered by the programme as reported by programme users and the providers. The programme users reported being very satisfied while the providers reported being satisfied with the services provided. None of the respondents reported being either unsatisfied or very unsatisfied with the programme.

\section{Discussion}

The new paediatric clinic facility has not only increased the ability of the staff to attend to more patients, but has also provided an environment conducive to providing optimal paediatric HIV care as well as training of health care personnel of different cadres on paediatric HIV/ AIDS. Laboratory services that include CD4+ cell count, HIV RNA measurements and chemistries are provided by 
$\mathrm{KCH}$ free of charge and also by the UNC Project at a fee borne by the programme to facilitate early staging, diagnosis and management of the patients. Without this kind of collaboration between various partner and stakeholders, it would not have been possible for the programme to offer such high quality and specialized service to a great number of children in such a short time since these essential laboratory services are not yet available at the COE. Since very few healthcare facilities in Malawi have this level of both material and human resources, training of health care cadres other than medical doctors in paediatric HIV care has proved to be a key component of the programme in the process of scaling up paediatric HIV care in Malawi and ensuring sustainability of the programme after the American paediatricians have left Malawi. We have learned that training other cadres of healthcare personnel on paediatric HIV care is feasible, affordable, and a way of ensuring sustainability of paediatric HIV care within the Malawi healthcare system.

Outcomes of this programme indicate that there is a clear benefit of providing ARVs to HIV-infected children. The baseline mean absolute CD4+ and percent nearly doubled from 562 to 1280 cells $/ \mathrm{mm}^{3}$ and $14 \%$ to $28 \%$ respectively in period of about two years. It was however not possible to explore the temporal relationship between immunologic changes (laboratory data) and clinical outcomes since we could not clearly link the laboratory dates to specific clinic visits such as 6th month, 12th month, 18th month visit and so on. Furthermore, only thirty-nine patients were referred for viral load testing suggesting that CD4 cell monitoring is an effective tool of monitoring ART in children.

The early mortality (first three months) reported in this study is in agreement with findings from a study on risk factors for early mortality in children on fixed-dose combination ART reported from Malawi ${ }^{6}$. Early identification and prompt management of HIV-infected children is key to reducing early mortality. In a study carried out in the Southern part of Malawi, Zachariah et.al ${ }^{7}$ concluded that community support might be associated with a considerably low death rate and overall better ART outcomes. An extension of the Baylor programme towards provision of community support may help reduce the early mortality in a similar manner.

The success of this programme in Malawi, and similar programmes sponsored by BIPAI in eight African countries has demonstrated that ART can be administered safely and effectively in developing countries. The expertise provided by the multidisciplinary programme staff, dedication shown by the caregivers and the continued support by programme partners has ensured that the programme continues to grow and provide hope to HIV-infected and HIV-exposed Malawian children. This programme is a testimony of reduction in stigma and discrimination associated with HIV/AIDS in Malawi, as evidenced by the fact that hundreds of patients accessing services from a facility that is publicly known to be dedicated to paediatric HIV care. This programme has demonstrated that ART can be administered safely and effectively to children, and provides a forum for more elaborate and sustained response to paediatric HIV/ AIDS care in Malawi.

\section{Acknowledgement}

We wish to thank the Abbott Fund, Ministry of Health, UNICEF, and other partners for their continued support of the programme. Special thanks to all the COE staff, patients, and dedicated caregivers who have all contributed to the success of the programme and participating in the internal evaluation exercise.

\section{References}

1. UNAIDS. AIDS epidemic update. November 2007.

2. UNAIDS. Malawi. Available online at http://www.unaids.org/en/ Regions_Countries/Countries/malawi.asp.

3. National AIDS Commission (NAC). Treatment of AIDS: Guidelines for the use of antiretroviral therapy in Malawi. Ministry of Health, Malawi. 2nd edition 2006. [NAC \& MOH HIV unit]

4. BIPAI. Malawi: Programme overview. Available online at http:// bayloraids.org/gap/. Accessed online November 10, 2007.

5. HIV Curriculum for the health professional. Baylor College of Medicine International Pediatrics AIDS Initiative (BIPAI) 2007, 3rd edition.

6. Zachariah R, Teck R, Buhendwa L, Fitzerland M, Labana S, Chinji $\mathrm{C}$, Humblet $\mathrm{P}$, and Harries AD. Community support is associated with better antiretroviral treatment outcomes in a resource-limited rural district in Malawi. Transactions of the Royal Society of Tropical Medicine and Hygiene. 2007; 101 (1):79-84.

7. Bong C, Yu JK, Chiang H, Huang W, Hsieh T, Schouten E, Makombe S, Kamoto K, Harries A. Risk factors for early mortality in children on adult fixed-dose combination antiretroviral treatment in a central hospital in Malawi. AIDS . 2007;21(13):1805-1810. 